\title{
THE OCEANOGRAPHY OF THE BRAS D'OR LAKES: GENERAL INTRODUCTION'
}

In March, 1996 the Cape Breton First Nation communities organized a workshop focussing on the Bras d'Or Lakes watershed to discuss the ecological research and monitoring and to develop a strategy to initiate projects arising out of the meeting. Six of the authors in this volume participated in this workshop. Subsequently, a number of general meetings have been held in Cape Breton; smaller groups, discussing the oceanography, have met at Bedford Institute. These meetings led to the 1999 Bras d'Or Lakes Ecosystem Workshop that set out 11 recommendations that identified priority items for scientific research (Lambert, 1999). In addition to the science issues that arose, the local involvement in these meetings, the interest shown, and the effort the community extended to understand the oceanography have been impressive. This positive feedback, along with current scientific activity, motivated us to propose an issue of the Proceedings of the Nova Scotian Institute of Science (NSIS) devoted to the oceanography of the Bras d'Or Lakes (Fig 1). Our goals are to provide a review of current knowledge of the oceanography of the Lakes and to present new data and

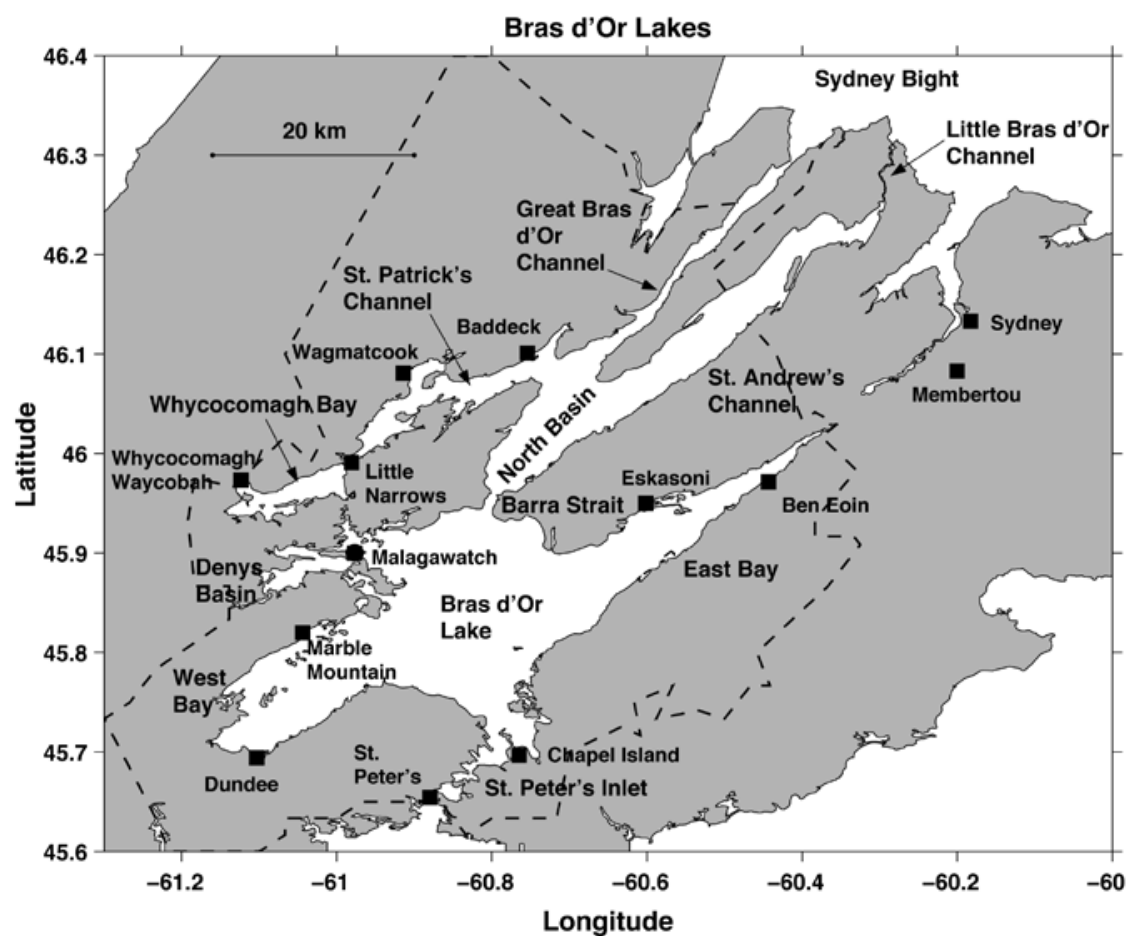

Fig 1 Map of the Bras d'Or Lakes indicating place names used in the text and the statistical area (broken line) of the 1996 Statistics Canada survey.

Prepared by Brian Petrie, Ocean Sciences Division, Bedford Institute of Oceanography, Dept. of Fisheries and Oceans, Dartmouth, Nova Scotia 
analyses to a broader community interested in the Lakes but one that may not have an extensive oceanographic background. This review builds on a conference focussed on aquaculture held in Sydney in 1975 (McKay, 1975).

A question that frequently arises is whether the Lakes are brackish water lakes or an inland sea. In their classic book on oceanography, Sverdrup, Johnson and Flemming (1942) tabulate the surface areas and volumes of the marginal (at the edges of the oceans) and mediterranean (inland) seas. The seas had 70 to 2100 times greater surface area than the Bras d'Or Lakes, and 125 to 100,000 times the water volume. Given their present area, the Lakes would require an average depth of $3700 \mathrm{~m}$ to equal the volume of the smallest sea in the tabulation. Given their average depth of about $30 \mathrm{~m}$, the Lakes would have to have a surface area equal to $60 \%$ of the surface area of the Gulf of St. Lawrence to equal the volume of the smallest sea. If we choose to call the Lakes an inland sea, then clearly it would be a very small one. On the other hand, Pickard (1979) defines an estuary as "a semi-enclosed coastal body of water having a free connection to the open ocean and within which sea-water is measurably diluted with fresh water deriving from land drainage". This definition is very broad, but as it captures the essence of the water properties of the Lakes, I conclude that the most suitable descriptive term for them is "estuary".

Two things in particular surprised me while acting as guest editor of this volume. I had thought that the deep areas of St. Andrew's Channel (to $280 \mathrm{~m}$ ) were caused by scouring during the advance and retreat of glaciers. Shaw et al. (2002), however, report that the deep areas may have been salt outcrops that dissolved when they contacted ground water. The second surprise comes from their re-creation of the shoreline of the Lakes (their Fig 12 and 13) when sea level was $25 \mathrm{~m}$ lower than at present, about 6000 to 9500 years ago (Fig 2A, B). St. Patrick's Channel was a river with small lakes where Whycocomagh Bay is now. Denys Basin and the northwestern portion of Bras d'Or Lake were dry land. East Bay was a lake joined to a much smaller bay. The only connection to the ocean was through the Little Bras d'Or Channel. They believe that the Little Bras d'Or Channel is filled with sediment now, making it the secondary connection to the ocean relative to Great Bras d'Or Channel. The water properties of the Lakes would certainly have been quite different from what they are now.

As the Lakes are a fundamental part of the environment for the people in the surrounding countryside, a brief overview of social aspects of the region is included as part of an extended introduction.

\section{The Regional Context ${ }^{2}$}

Inland bodies of water have an influence on, and are influenced by, the activities of people around them. Consequently, any study of the Bras d'Or Lakes would be incomplete without reference to the socioeconomic features of the surrounding area (Fig 1). The difficulty, however, is a lack of available data. Most data collection has been done by municipal or county groupings and data have not been compiled in a way that would indicate the cumulative interaction of people with the ecosystem of the Lakes. While it is self evident that the impacts of this interaction would be substantial, they have yet to be studied.

2 Prepared by Janice Raymond, Policy and Economics Branch, Maritimes Region, Department of Fisheries and Oceans, Marine House, Dartmouth, Nova Scotia. 

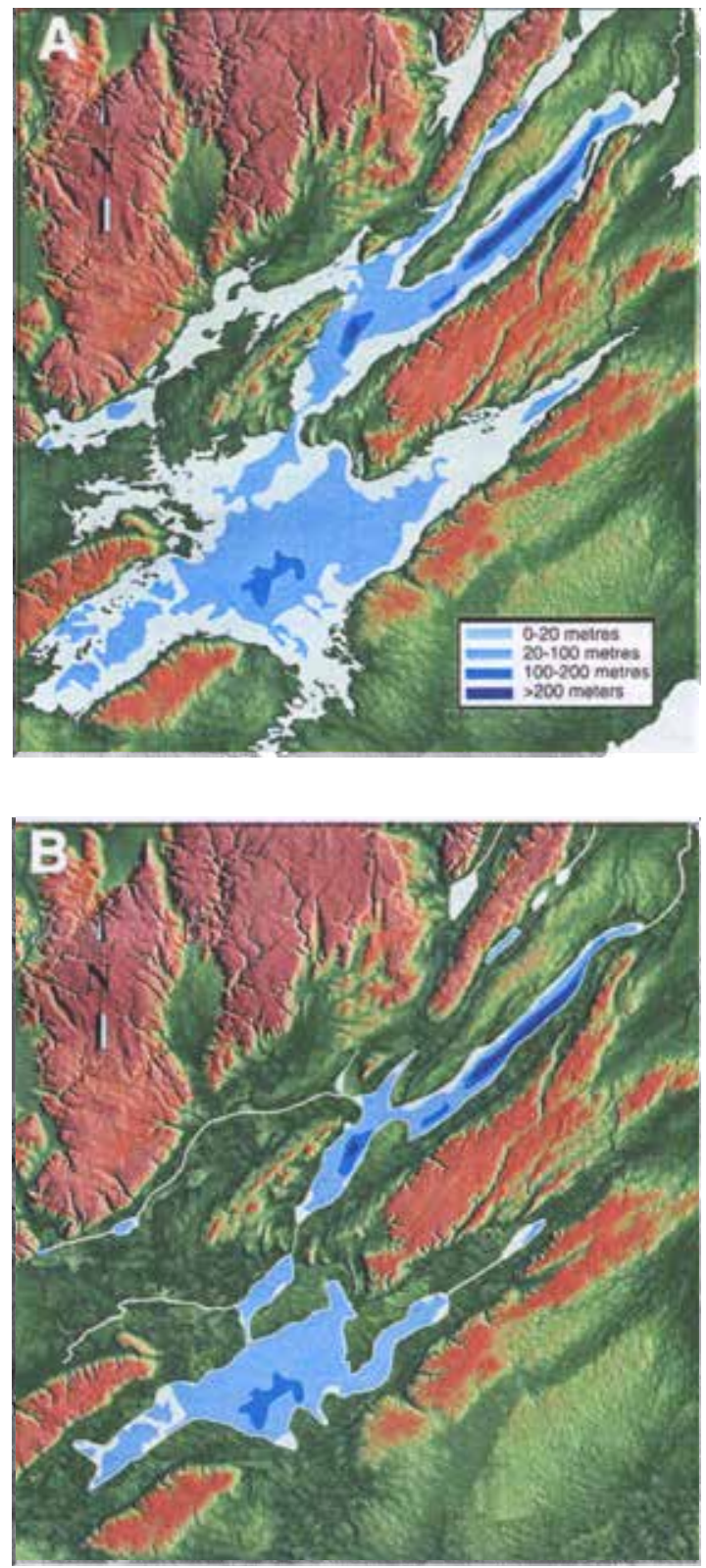

Fig 2 (A) Present shoreline of the Bras d'Or Lakes. (B) Shoreline 9500-6000 years before present (Shaw et al., 2002). For the land, dark green shading represents elevations less than $30 \mathrm{~m}$ above sea level, light green shades represent 30-150 $\mathrm{m}$ above sea level, and brown represents land $>150 \mathrm{~m}$ above sea level. 
Based on the Census of Canada, 1996, the population of the enumeration areas touching the shoreline of the Lakes was 13,725 (Fig 1). Most of the communities are small and unincorporated. With the exception of Eskasoni, individual community populations do not exceed 1,000 (Statistics Canada, 2001).

The region adjacent to the Bras d'Or Lakes is rural in character with a natural landscape that makes it an attractive recreational area. Commercial fishing and aquaculture industries are based on the resources of the Lakes and contribute to the regional economy. Recreational activities, particularly fishing and boating, are sources of income as well as enjoyment for inhabitants and tourists. On an industry basis, the services sector is the largest employer in the Lakes region (Fig 3). Unemployment, however, is an ongoing problem amounting to $27.8 \%$ of the workforce in the 1996 census and is a factor driving many of the local efforts aimed at economic improvement. The community of Baddeck (population 937), on the northern side of the Lakes, is located on a tourist route through the Island to Cape Breton Highlands National Park and the Cabot Trail. Baddeck is a popular recreational area, highlighted by a Historic Park commemorating Alexander Graham Bell.

On the northern side of the Island, the Great Bras d' Or Channel is one of the major connections between the Lakes and the ocean. Shipments of gypsum mined at Little Narrows pass through here. At St. Peter's, on the southern side, a man-made canal connects the Lakes to the ocean. Marble Mountain, as the name implies, was once a

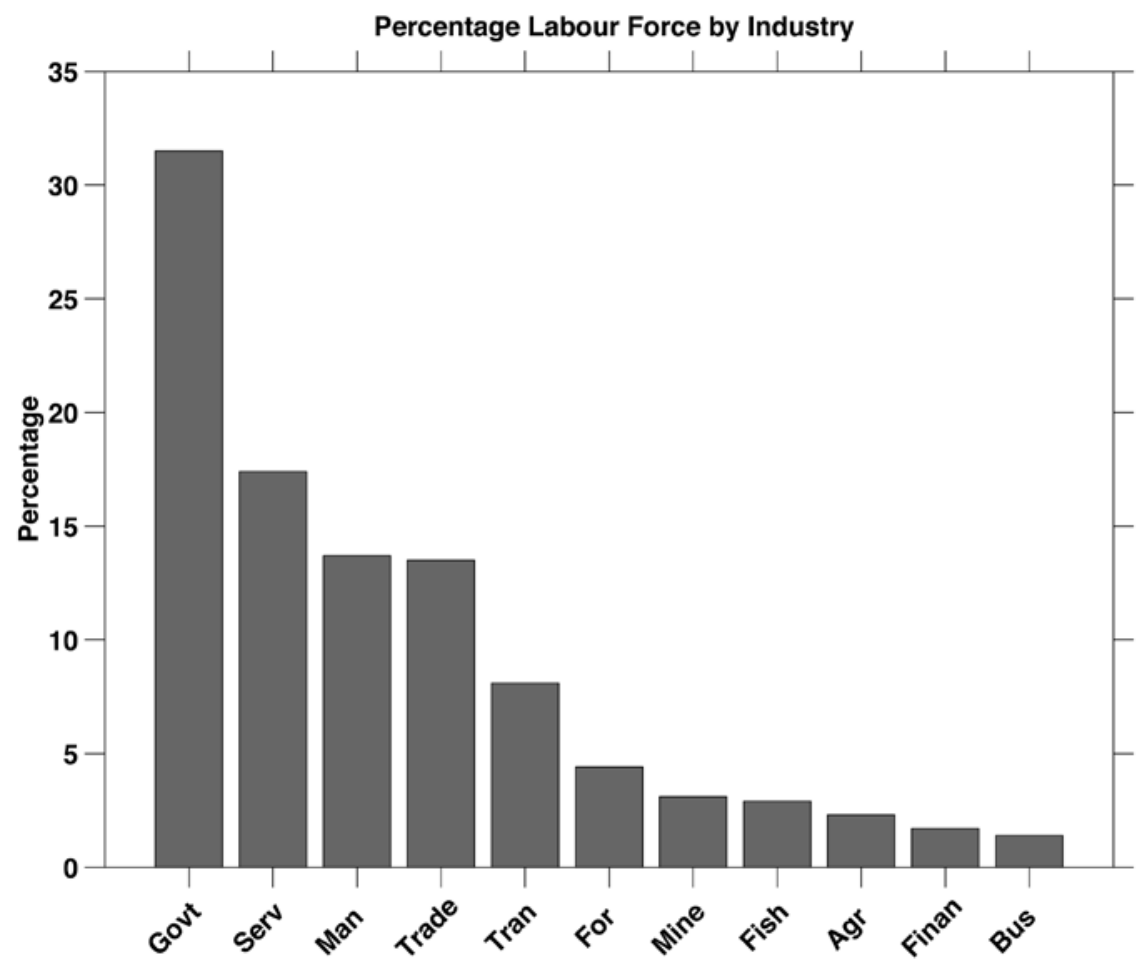

Fig 3 Percentage labour force by industry based on the 1996 Statistics Canada survey. 
marble quarry. The heritage of the $\mathrm{Mi}^{\prime} \mathrm{kmaq}^{3}$ and early Scottish settlers is reflected in names like Whycocomagh and Eskasoni, or Ben Eoin and Dundee, respectively.

Aboriginal identity is strong in the Lakes region where five Mi'kmaw communities are located (Fig 1). The 1996 census (Statistics Canada 2002) indicated that the largest First Nation community was Eskasoni $(2,504)$, followed by Whycocomagh/Waycobah (574), Wagmatcook (448), and Chapel Island (350). The fifth community of Membertou (612), while not situated on the shoreline also has a significant tie to the Lakes. One direct example of that link is through Malagawatch, which is reserve land that was set aside in 1958 for joint use by each of the five communities (Howe, 2002). The Mi'kmaw language is spoken by 3,400 people in the Bras d'Or Lakes area.

The distribution of the population by age group (Fig 4) is similar to the Cape Breton and provincial profiles in most respects. The percentage of the population under 25 is $6.3 \%$ higher for the Bras $d^{\prime}$ Or Lakes region than for the province as a whole.

\section{Percentage Population by Age Groups}

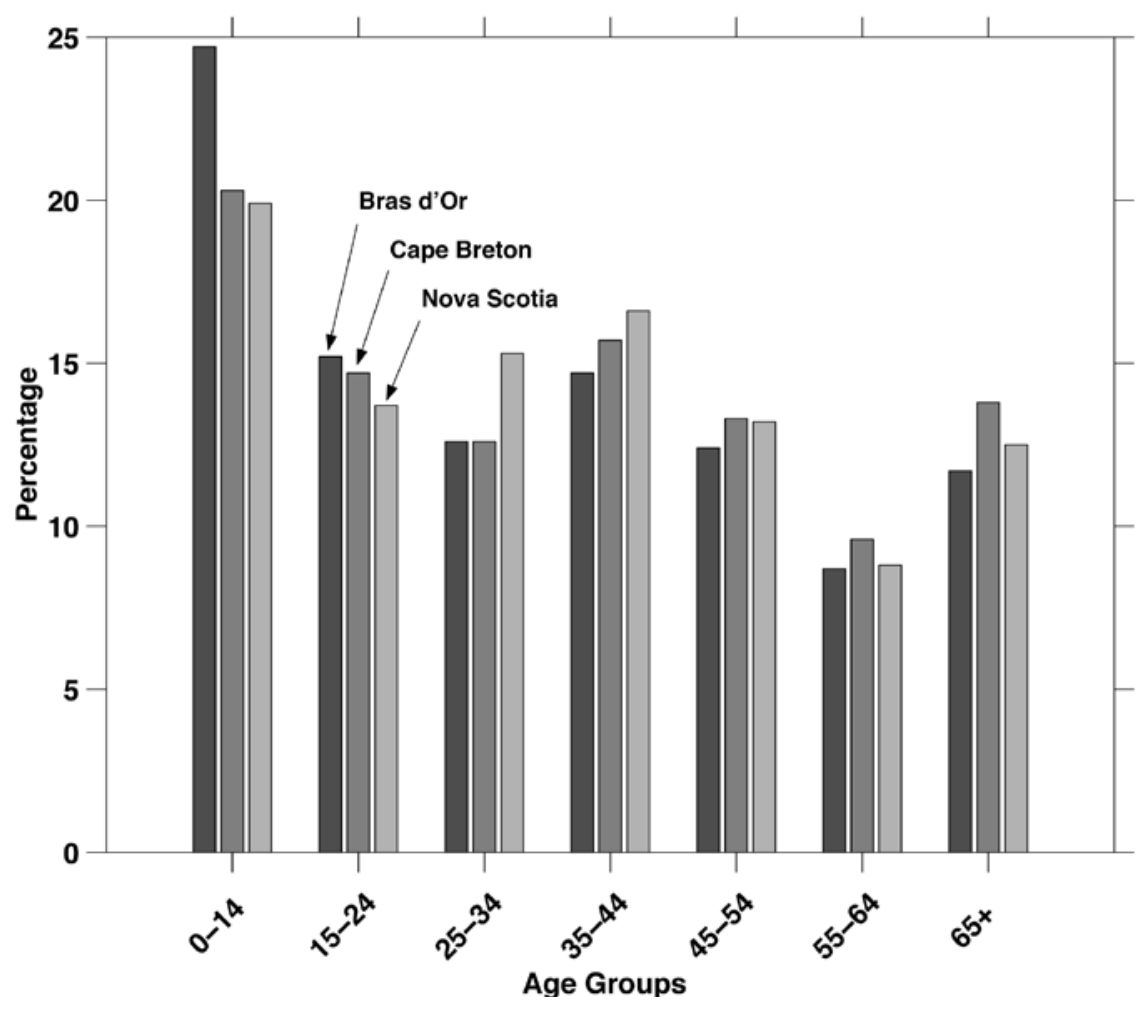

Fig 4 Percentage distribution of population by age group for the Bras d'Or Lakes (dark grey bar), Cape Breton Island (medium grey) and Nova Scotia (light grey) based on the 1996 Statistics Canada survey.

\footnotetext{
3 Use of the terms Mi'kmaq and Mi'kmaw conforms to that described in the Mi'kmaw Resource Guide (1997) whereby "Mi'kmaw" is the singular of "Mi'kmaq". "Mi'kmaw" is also used as an adjective where it precedes a noun such as Mi'kmaw people, Mi'kmaw person etc.
} 
Although the census provides a convenient method of defining the area, there is bound to be some distortion because parts of the enumeration areas covered are quite removed from the Lakes. The watershed may be more appropriate since the rivers in that area flow into the Lakes and disturbances initiated there could have serious impacts. It is more relevant to refer to the watershed on issues relating to the sustainable management of the ecosystem. Methodology is needed to enable estimates to be made of socioeconomic aspects extrapolated from data already collected on the basis of other categories or groupings.

An examination of the commercial and recreational uses of the Lakes and the potential conflicts among uses are important areas for study. A comparative study, perhaps with other similar lake regions, would be useful in determining what social demographic characteristics would advance an understanding of the region. For example, a sociological study might focus on determining the implications of such factors as population density, education or income distributions to provide more understanding of the relationships between the people living in the area of the Lakes and the impacts of the Lakes' resources. An economic assessment of the value of the Lakes would help to clarify their importance and emphasize the point that, as well as aesthetic values, there are economic incentives to protect the Lakes from contamination or other destructive exploitation.

An economic assessment is currently being proposed by the Bras d'Or Stewardship Society (Bates, 2002). The Society, which has a Board of Directors and a membership of about 200, was incorporated under the Nova Scotia Societies Act in 1997. While work is done primarily on a volunteer basis, the Society organizes specific projects that are cost-shared with various levels of government. The main effort is towards the reduction and elimination of the discharge of untreated sewage into the Lakes. It works with other organizations, particularly neighbouring First Nations communities, to promote the protection and conservation of the Lakes. The proposal to assess the contribution of the economy of the watershed area covers the shellfish fishery, aquaculture, the tourism industry, commercial shipping industry and the recreational sector. This study would be an important step in increasing awareness and understanding of the regional context of the Lakes.

\section{Direction of Future Oceanographic Studies ${ }^{4}$}

There has been considerable oceanographic research in the Bras d'Or Lakes for the past several years and it is anticipated that work will continue into the near future. This volume presents results from these and reviews of earlier related studies. It has also given the opportunity to consider the next steps future studies could take that would build on current and past efforts. These steps are outlined below by discipline.

Physical oceanography. The development of a fine scale circulation model of the Lakes driven by freshwater inflow, wind, tides and external forcing from Sydney Bight is an attainable goal. The oceanographic database essential to evaluate the model's performance is sizable and growing. Moreover, the nearly fully enclosed nature of the Lakes makes boundary conditions easier to handle than for the open ocean. The model should be able to incorporate natural and human-derived inputs and thereby contribute to water quality issues in the Lakes, identified by the 1999 Bras d'Or Lakes Ecosystem Workshop as the "overriding problem in the Bras d'Or Lakes". A project (fall 2000 to fall 2002) in St. Andrew's Channel and Bras d'Or Lake will address the overall

\footnotetext{
4 Prepared by Brian Petrie from submissions provided by authors of individual articles
} 
heat budget and the role of wintertime convection in deep water renewal in the Lakes. However, observations of ice thickness are not being made and are an important element of these problems.

Chemical oceanography. Research over the last several decades has provided sufficient information to understand the distribution of dissolved oxygen, the sources and distributions of nutrients, and some aspects of the role of nutrient supply in the biological productivity of the Lakes ecosystem. The almost complete lack of winter data means that two important processes in the nutrient and oxygen cycles are not well understood. The first is the increase in nutrient levels in the surface layer through the winter that provides most of the nutrients that fuel the spring bloom. Understanding the productive capacity of the Lakes will require nutrient observations in late winter and direct measurements of the bloom. The second process is the renewal of deep waters in the major basins. The dissolved oxygen data clearly indicate that even the deepest waters in St. Andrew's Channel are periodically renewed, but the mechanisms and frequency of this renewal are not known. Comparing oxygen data from the 1990s with the limited data from the 1970s suggests that there may be long term variations in deep water properties consistent with irregular replacement of these deep waters. Recent winter measurements of physical properties of deep water coupled with wintertime measurements of nutrients and oxygen will help to improve the understanding of deep water renewal.

Invertebrate community. Fundamental questions remain regarding the community of epibenthic invertebrates in the Lakes including the species composition and the factors that determine it. The benthic invertebrates are of interest not only because they include commercial species, but because of their ecological roles in recycling detritus and as a food source for other species including groundfish. Future research should include studies of spatial and seasonal changes in species composition in relation to the physical environment. Habitat maps, e.g. from multibeam bathymetry, will aid planning benthic surveys and significantly advance our understanding of animal-habitat linkages. Studies of the population biology of lobsters, crabs and oysters are of interest because these species are important components of the ecosystem, economically valuable, and serve as models for species with similar life histories. To understand why, for example, lobster landings are lower in the Lakes compared with the open Cape Breton coast, studies are needed of lobster distribution, movement, condition and production in both areas. Such studies should cover the full range of the life history of the lobster.

Plankton and fish. Our knowledge of the fish in the Lakes is quite extensive and that of the zooplankton improving rapidly. A zooplankton survey is underway and samples are being analysed; however, counting and identifying planktonic species is a slow process; considerable time will elapse before these studies are completed. Knowledge of the phytoplankton community is minimal but will improve as the results from studies underway and planned are realized.

Marine geology. Future work on the glacial and early post-glacial history of the Lakes will require piston coring or drilling from a ship or winter ice platform into older sediments and subsequent radiocarbon dating. Correlations must be established with the long boreholes in clay recently acquired by the Nova Scotia Dept. of Natural Resources in the areas to the west of the Bras d'Or Lakes. Additional high-resolution seismic reflection profiles are needed to identify features revealed by multibeam bathymetry. Furthermore, it is vital that backscatter data, indicative of sea-floor reflectivity, be integrated with multibeam imagery and ground-truth information to enhance our understanding of bottom materials. The Geological Survey of Canada is 
developing standards for interpretive maps (including a habitat map) based on multibeam bathymetry. It is hoped that maps of the Bras d'Or Lakes will be among the first to be produced using this new system.

Shore dynamics and evolution. We have observed that the depositional shore features in the Bras d'Or Lakes evolve through a cycle of growth, stabilization, breakdown and collapse. Field surveys of the physical characteristics and determination of the age of existing barriers are required to confirm the model of coastal barrier evolution. The impacts of sea ice on the growth and stability of coastal barriers requires further investigation. New multibeam bathymetric images collected by the Canadian Hydrographic Service show spectacular examples of similar depositional features preserved underwater throughout the Lakes. These submerged shore features provide information for mapping the paleo-shorelines and their elevation relative to present sea level. They will help to map the existence of individual lakes in the basin and when they became linked to each other. The paleo-shoreline maps can be used to select the best sediment coring locations where datable material may occur leading to a more accurate analysis of sea level history and shoreline evolution of the Lakes. This information has great significance for researchers looking for archaeological sites or physical features such as old river channels.

\section{Acknowledgements}

We thank Dr. James E. Stewart, editor of the Proceedings, for his encouragement throughout the production of this volume and for his editorial assistance. We thank the external reviewers for their constructive criticism of the science and for their suggestions of how to make the science more accessible to the general public.

\section{References}

Bates, P. 2002. (Bras d'Or Stewardship Society). Personal communication and project proposal.

Howe, T. 2002. (Aboriginal Fisheries, Department of Fisheries and Oceans). Personal communication.

Lambert, T. 1999. Bras d'Or Lakes Ecosystem Workshop. Unpublished manuscript, 47 pp.

McKay, G. 1975. Ed., "The Proceedings of the Bras d'Or Lakes Aquaculture Conference", College of Cape Breton Press, Sydney, N. S., 312 pp.

Mi'kmaw Resource Guide, 2nd Ed. 1997 Eastern Woodland Publishing, Truro, Nova Scotia.

Pickard, G.L. 1979. Descriptive Physical Oceanography: An Introduction. 3rd Ed., Pergamon Press, Oxford, 233 pp.

Statistics Canada 2001 "Data profiles for the Bras d'Or Lakes area", Census of Canada, 1996.

Statistics Canada 2002. Community profiles menu, HREF="http://www.statcan.ca"

Shaw, J., Piper, D.J.W. and Taylor, R.B. 2002. Marine Geology of the Bras d'Or Lakes, Nova Scotia; Proc. N. S. Inst. Sci., 42, 127-147.

Sverdrup, H.U., Johnson, M.W. and Flemming, R.H. 1942. The Oceans Their Physics, Chemistry and General Biology. Prentice-Hall, New York, 1087 pp.

(Received 27 June 2002) 